\title{
Exogenous Anandamide Protects Rat Brain against Acute Neuronal Injury In Vivo
}

\author{
M. van der Stelt, ${ }^{1}$ W. B. Veldhuis, ${ }^{2,3}$ G. W. van Haaften, ${ }^{1}$ F. Fezza, ${ }^{4}$ T. Bisogno, ${ }^{4}$ P. R. Bär, ${ }^{3}$ G. A. Veldink, ${ }^{1}$ \\ J. F. G. Vliegenthart, ${ }^{1}$ V. Di Marzo, ${ }^{4}$ and K. Nicolay ${ }^{2}$ \\ ${ }^{1}$ Department of Bio-organic Chemistry, Bijvoet Center for Biomolecular Research, Utrecht University, 3584 CH Utrecht, \\ The Netherlands, ${ }^{2}$ Department of Experimental In Vivo Nuclear Magnetic Resonance, Image Sciences Institute, Utrecht \\ University Medical Center, 3584 CJ Utrecht, The Netherlands, ${ }^{3}$ Department of Experimental Neurology, Utrecht University

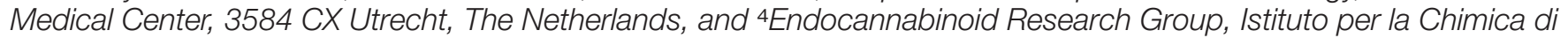 \\ Molecole di Interesse Biologico, Consiglio Nazionale delle Ricerche, 80078 Pozzuoli, Naples, Italy
}

The endocannabinoid anandamide [ $N$-arachidonoylethanolamine $(A E A)]$ is thought to function as an endogenous protective factor of the brain against acute neuronal damage. However, this has never been tested in an in vivo model of acute brain injury. Here, we show in a longitudinal pharmacological magnetic resonance imaging study that exogenously administered AEA dose-dependently reduced neuronal damage in neonatal rats injected intracerebrally with the $\mathrm{Na}^{+} / \mathrm{K}^{+}$-ATPase inhibitor ouabain. At 15 min after injury, AEA (10 mg/kg) administered 30 min before ouabain injection reduced the volume of cytotoxic edema by $43 \pm 15 \%$ in a manner insensitive to the cannabinoid $\mathrm{CB}_{1}$ receptor antagonist SR141716A. At $7 \mathrm{~d}$ after ouabain treatment, $64 \pm 24 \%$ less neuronal damage was observed in AEA-treated $(10 \mathrm{mg} / \mathrm{kg}$ ) rats compared with control animals. Coadministration of SR141716A prevented the neuroprotec- tive actions of AEA at this end point. In addition, (1) no increase in AEA and 2-arachidonoylglycerol levels was detected at 2, 8, or $24 \mathrm{hr}$ after ouabain injection; (2) application of SR141716A alone did not increase the lesion volume at days 0 and 7 ; and (3) the AEA-uptake inhibitor, VDM11, did not affect the lesion volume. These data indicate that there was no endogenous endocannabinoid tone controlling the acute neuronal damage induced by ouabain. Although our data seem to question a possible role of the endogenous cannabinoid system in establishing a brain defense system in our model, AEA may be used as a structural template to develop neuroprotective agents.

Key words: anandamide; 2-AG; astrogliosis; cannabinoid; excitotoxicity; ischemia; magnetic resonance imaging; neonatal rat; neuronal injury; neuroprotection; ouabain
The CNS is highly vulnerable to ischemia. Neuronal death caused by ischemia is executed via a complex array of processes in which excitotoxicity plays a major role. In excitotoxicity, cell death is triggered by the overstimulation of excitatory amino acid receptors. This leads to cytotoxic levels of calcium and to subsequent activation of destructive pathways, involving among others caspases, calpains, and the generation of reactive oxygen species (Dirnagl et al., 1999; Doble, 1999).

Compounds that interfere with excitotoxicity may be used as neuroprotective therapeutic agents. Interestingly, the brain has various endogenous protection factors at its disposal (e.g., adenosine, melatonin, and estrogens) (Reiter, 1998; Hurn and Macrae, 2000; Picano and Abbracchio, 2000). Several reports have also revealed a connection between the endogenous lipid anandamide

\footnotetext{
Received June 28, 2001; revised Aug. 21, 2001; accepted Sept. 5, 2001.

W.B.V. is supported financially by the Netherlands Organization for Scientific Research, Medical Sciences Council. V.D.M. is supported in part by the Ministero per l'Universita' e Ricerca Scientifica e Tecnologica 3933. We are indebted to H. Veldman and G. van Vliet for expert technical assistance. We thank Sanofi Recherche for the gift of SR141716A, Dr. R. van Sluis for the development of the data-processing program, and Dr. R. A. H. Adan for the cell culture facilities.

M.v.d.S. and W.B.V. contributed equally to the work.

Correspondence should be addressed to G. A. Veldink, Department of Bioorganic Chemistry, Bijvoet Center for Biomolecular Research, Padualaan 8, Utrecht University, 3584 CH Utrecht, The Netherlands, E-mail: veldink@accu.uu.nl; or V. Di Marzo, Endocannabinoid Research Group, Istituto per la Chimica di Molecole di Interesse Biologico, Consiglio Nazionale delle Ricerche, Via Campi Flegrei 34, Ex Comprensorio Olivetti, Fabbricato 70, 80078 Pozzuoli, Napoli, Italy, E-mail: vdimarzo@icmib.na.cnr.it.

Copyright (C) 2001 Society for Neuroscience $0270-6474 / 01 / 218765-07 \$ 15.00 / 0$
}

[ $N$-arachidonoylethanolamine (AEA) $]$ and neurodegenerative diseases (H. S. Hansen et al., 1998, 2000; Di Marzo et al., 2000b; Baker et al., 2001).

AEA mimics in part the actions of $\Delta^{9}$-tetrahydrocannabinol (THC), the psychoactive compound in marijuana. Together with 2-arachidonoylglycerol (2-AG), AEA represents a class of lipids, termed endocannabinoids because of their ability to activate the $\mathrm{CB}_{1}$ and $\mathrm{CB}_{2}$ cannabinoid receptors. AEA is rapidly translocated into the cell via a transporter protein and is then immediately inactivated by a fatty acid amide hydrolase (FAAH) (Pertwee, 1997; Di Marzo et al., 1998).

Several lines of evidence indicate that AEA can serve to protect the brain against neuronal injury (H. S. Hansen et al., 1998, 2000): (1) AEA and its precursor $N$-arachidonoylphosphatidylethanolamine are normally found in low concentrations in the brain, but their levels increase in a calcium-dependent manner postmortem and with severe neuronal injury (Schmid et al., 1990; Kempe et al. 1996; Hansen et al., 1999; H. H. Hansen et al., 2000, 2001; Sugiura et al., 2000); (2) exogenous AEA protects cerebral neurons from in vitro ischemia (Sinor et al., 2000); (3) $\mathrm{CB}_{1}$-mediated closing of $\mathrm{N}$ - and $\mathrm{P} / \mathrm{Q}$-type calcium channels protects neurons against in vitro secondary excitotoxicity (Shen et al., 1996; Shen and Thayer, 1998); (4) we have demonstrated recently that $\mathrm{THC}$ can reduce neuronal damage via the $\mathrm{CB}_{1}$ receptor in an in vivo model of excitotoxicity (Van der Stelt et al., 2001); (5) WIN55.212, a synthetic cannabinoid, protected rat brains against focal and global ischemia (Nagayama et al., 1999); and (6) $\mathrm{CB}_{1}$ 
expression is enhanced in the cortical mantle zone in rats after ischemia (Jin et al., 2000). As yet, in vivo neuroprotection by AEA has never been reported.

To date no effective drugs are available to treat brain injury after transient (global) or permanent focal cerebral ischemia. Insights into how the brain defends itself may lead to novel strategies to develop new therapeutic agents. Therefore, it was our goal to test whether the endogenous cannabinoid system affords the brain protection in an in vivo model of neuronal injury. In this study we combined longitudinal pharmacological magnetic resonance imaging (MRI) and isotope dilution gas chromatography/mass spectrometry (GC/MS) techniques. Our data indicate that there is no endogenous endocannabinoid tone controlling the acute neuronal damage induced by ouabain, a $\mathrm{Na}^{+} / \mathrm{K}^{+}$-ATPase inhibitor, although exogenous AEA can effectively reduce toxininduced injury in the neonatal rat brain.

\section{MATERIALS AND METHODS}

Animal model. The neonatal rat brain was used to test the neuroprotective effects of endocannabinoids because it has been widely studied in various models of cerebral ischemia and excitotoxicity (Vannucci, 1990; van Lookeren Campagne et al., 1994; Dijkhuizen et al., 1996; Renolleau et al., 1998; Hansen et al., 2001). Neonatal Wistar rats (U:Wu/Cpb; 7-8 $\mathrm{d}$ of age) were anesthetized with ether and immobilized in a stereotaxic frame. A small burr hole was drilled in the cranium over the left hemisphere, $2.5 \mathrm{~mm}$ lateral to bregma. A $1 \mu \mathrm{l}$ syringe was lowered into the left striatum to a depth of $4.0 \mathrm{~mm}$ (Dijkhuizen et al., 1996). Ouabain (0.5 $\mu \mathrm{l} ; 1 \mathrm{~mm}, n=61$; Sigma Aldrich, Zwijndrecht, The Netherlands) or vehicle $(0.5 \mu \mathrm{l}, 40 \mathrm{~mm}$ Tris- $\mathrm{HCl}$ buffer, $\mathrm{pH} 7.4 ; n=8)$ was injected at a rate of $0.125 \mu \mathrm{l} / \mathrm{min}$ using a microdrive. After injection, the needle was left in situ for 2 min to avoid leakage of injection fluid from the needle tract. Body temperature was maintained at $37^{\circ} \mathrm{C}$ using a water-filled heating pad and an infrared heating lamp to compensate for AEAinduced hypothermia. Animals needed for MRI study were then positioned in the magnet and anesthesia was continued using a mixture of halothane $(0.4-1 \%)$ in $\mathrm{N}_{2} \mathrm{O} / \mathrm{O}_{2}$.

Pharmacological treatments. Animals used for the MRI study were treated intraperitoneally with anandamide ( 1 or $10 \mathrm{mg} / \mathrm{kg} ; n=5$ and 6 , respectively; Biomol, Heerhugowaard, The Netherlands), anandamide plus SR141716A (10 and $3 \mathrm{mg} / \mathrm{kg} ; n=4$; Sanofi Recherche, Montpellier, France), SR141716A alone ( $3 \mathrm{mg} / \mathrm{kg} ; n=5)$, the selective AEA membrane transporter inhibitor VDM11 (10 mg/kg; $n=5)$, synthesized as described previously (De Petrocellis et al., 2000), or vehicle alone $(n=$ 12) (all drugs in $1 \mathrm{ml} / \mathrm{kg}$ body weight $18: 1: 1 \mathrm{v} / \mathrm{v}$ PBS/Tween 80/ethanol) $30 \mathrm{~min}$ before toxin injection. There was no difference in body weight and growth rate between any of the groups. Utrecht University's Animal Experimentation Committee approved all protocols.

MRI experiments. MRI was performed on a $4.7 \mathrm{~T}$ Varian horizontal bore spectrometer. Excitation and signal detection were accomplished by means of a Helmholtz volume coil $(9 \mathrm{~cm})$ and an inductively coupled surface coil $(2 \mathrm{~cm})$, respectively. A single-scan diffusion-trace MRI sequence [four $b$ values $=100-1300 \mathrm{sec} / \mathrm{mm}^{2}$; repetition time $(\mathrm{TR})=3$ sec; echo time $(\mathrm{TE})=100 \mathrm{msec}]$ was used to generate quantified images of the tissue water trace apparent diffusion coefficient (ADC). Diff usiontrace and $\mathrm{T}_{2}$-weighted imaging $(\mathrm{TE}=18,40,62$, and $84 \mathrm{msec}$; $\mathrm{TR}=2$ sec; number of transients $=2)$ were performed in all animals $(2.2 \times 2.2$ $\mathrm{cm}$ field of view, $64 \times 64$ datamatrix), starting at $t=15 \mathrm{~min}$ after injection on day 0 ; both types of imaging were repeated 1 week later. As expected, no changes in $\mathrm{T}_{2}$-weighted MRI were detected at this early time point. Both the $\mathrm{T}_{2}$-weighted and the diffusion-weighted datasets consisted of seven consecutive, $1.5-\mathrm{mm}$-thick slices with a $0 \mathrm{~mm}$ slice gap. To minimize interference at the slice boundaries, slices were acquired in alternating order $(1,3,5,7,2,4,6)$, thus maximizing the time between excitation of two neighboring slices. For the diff usion-weighted imaging we used a double spin-echo pulse sequence with four pairs of bipolar gradients with specific predetermined signs in each of the three orthogonal directions, as described recently (de Graaf et al., 2001). The combination of gradient directions leads to cancellation of all off-diagonal tensor elements, thus effectively measuring the trace of the diffusion tensor. This provides unambiguous and rotationally invariant ADC values in one experiment, circumventing the need for three separate exper- iments. For each $b$ value, two scans were averaged. The total scan time for acquisition of seven slices with four $b$ values and two averages was $17 \mathrm{~min}$.

Data analysis. ADC and $\mathrm{T}_{2}$ maps were generated by monoexponential fitting using the Interactive Data Language software package (Research Systems Inc., Boulder, CO). Parametric images were analyzed in anatomic regions of interest using the same software package. Pixels in the ipsilateral hemisphere were considered pathological if their ADC value or $\mathrm{T}_{2}$ value differed more than twice the $\mathrm{SD}$ of the mean value in the contralateral hemisphere. The ventricles were segmented out in the average ADC and $T_{2}$ measurements. The lesion volume per slice was calculated by multiplying the lesion area (equaling the number of pathological pixels $\times$ field-of-view in $\mathrm{cm}^{2} /$ number of points acquired per image) by the slice thickness. The total lesion volume was obtained by summation of the lesion volumes for all slices. The absence of a slice gap makes interpolation of lesion areas between slices unnecessary, reducing systematic errors to within-slice "averaging" of signal intensity. Statistical analysis was performed using SPSS 9.0 (SPSS Inc., Chicago, IL). Differences between groups were analyzed using Student's $t$ test; reported $p$ values correspond to two-tailed significance.

Histology. After the last MRI measurements, animals needed for histology were transcardially perfused with $4 \%$ paraformaldehyde in 0.1 M PBS. Dissected brains were post-fixed overnight by immersion in the same fixative, cryoprotected in $10 \%$ sucrose in PBS for $24 \mathrm{hr}$ followed by $25 \%$ sucrose in PBS for $72 \mathrm{hr}$, and quickly frozen in liquid nitrogencooled isopentane. Coronal sections $(10 \mu \mathrm{m})$ were cut and stained for glial fibrillary acidic protein (GFAP), for Nissl substance, or with hematoxylin-eosin using standard procedures. The position of the histological slices was matched to the position of the MRI images by known position relative to bregma, after which a gross correlation was done.

Protein analysis. Mouse melanoma cells (B16-G4F) were transiently transfected with $6-10 \mu \mathrm{g}$ of recombinant cDNA (pcDNA3 vector) encoding the $\mathrm{CB}_{2}$ receptor (a kind gift from Dr. R. Delwel, Institute of Hematology, Erasmus University, Rotterdam, The Netherlands). Rat tissue (brain and spleen) and cells were homogenized and sonicated for $10 \mathrm{sec}$ three times in buffer containing (in mM): 50 Tris, 1 EDTA, and 3 $\mathrm{MgCl}_{2}, \mathrm{pH}$ 7.4. Membrane fractions were prepared by centrifugation at $5000 \times g$ for $5 \mathrm{~min}$. Samples were stored at $-20^{\circ} \mathrm{C}$ until further use.

Samples containing $30 \mu \mathrm{g}$ of protein were separated by $10 \%$ SDSPAGE (reducing) and transferred to a nitrocellulose membrane. Membranes were blocked overnight in $1 \%$ gelatin in PBS- $0.1 \%$ Tween $\left(\mathrm{CB}_{1}\right.$, FAAH) or in PBS- $0.1 \%$ Tween containing $5 \%$ nonfat milk powder $\left(\mathrm{CB}_{2}\right)$. Membranes were rinsed twice and washed once for $15 \mathrm{~min}$ and four times for $5 \mathrm{~min}$ each with $20 \mathrm{ml}$ of PBS-0.1\% T. The membranes were incubated with polyclonal primary antibodies for $3 \mathrm{hr}\left(1: 1000, \mathrm{CB}_{1}\right.$; Cayman Chemicals, Ann Arbor, MI), 2 hr (1:1000, CB ; $_{2}$ Cayman Chemicals) and $1.5 \mathrm{hr}$ (1:5000, FAAH; a kind gift from Dr. M. Maccarrone, University of Rome "Tor Vergata," Rome, Italy) and washed. A donkey anti-rabbit antibody conjugated to horseradish peroxidase (1:5000; BioRad, Richmond, CA) was used as a secondary antibody (1 hr incubation). Membranes were washed and developed with Western-blotting detection reagents (Amersham Pharmacia Biotech, Arlington Heights, IL) according to the manufacturer's manual.

Lipid extraction. Neonatal rats [postnatal day 7 (P7) and P8] injected intracerebrally with ouabain or vehicle were killed by decapitation at 0 , 2,8 , and $24 \mathrm{hr}$ after induction of excitotoxicity ( $n=6$ for each time point). The ipsilateral and contralateral hemisphere were rapidly removed and separately homogenized in $5 \mathrm{ml}$ of ice-cold Tris buffer (50 $\mathrm{mM}, \mathrm{pH}$ 7.4). Lipids were extracted according to the method of Bligh and Dyer (1959). One nanomole of $\mathrm{d}_{8}$-AEA and $1 \mathrm{nmol}$ of $\mathrm{d}_{8}-2-\mathrm{AG}$ (Cayman Chemicals) were added as internal standards. The organic phases were dried under nitrogen and purified by normal-phase HPLC performed as described previously (Bisogno et al., 1997). Mono-AGs and AEA standards were eluted after $18-23$ and $27-28 \mathrm{~min}$, respectively. The mono-AG fraction contained the 1-, (3)-, and 2-stereoisomers.

To limit postmortem accumulation of endocannabinoids, the time between decapitation and homogenization in cold organic solvents was kept as short and constant as possible $(<5 \mathrm{~min})$ and the tissues were kept on ice.

GC/MS analysis. HPLC fractions were dried under a flow of nitrogen and derivatized with $15 \mu \mathrm{l}$ of $N$-methyl- $N$-trimethylsilyl-trifluoroacetamide containing $1 \%$ trimethylchlorosilane for $2 \mathrm{hr}$ at room temperature, thus yielding the trimethylsilyl derivatives of AEA and 2-AG. The two derivatized fractions were analyzed by GC/MS performed as described previously (Bisogno et al., 1997, 1999). The derivatives of both deuterated and nondeuterated AEA, 2-AG, and 1-(3)AG standards were 
$\mathrm{CB}_{1}$

$\mathrm{CB}_{2}$
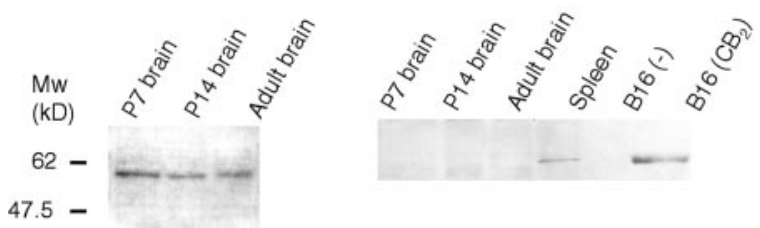

Figure 1. Western blot of $\mathrm{CB}_{1}$ and $\mathrm{CB}_{2}$ cannabinoid receptors and FAAH in the neonatal rat (P7 and $\mathrm{P} 14)$ and adult brain. $\mathrm{CB}_{2}$ receptor was absent in the rat brain but was detected in the spleen and in the $\mathrm{CB}_{2^{-}}$ transfected cell line.

eluted after 18, 19, and 19.5 min, respectively. MS detection was run in the selected ion-monitoring mode to improve sensitivity. Selected ions for AEA were at a mass to charge ratio $(\mathrm{m} / \mathrm{z})$ of 427 and 419 corresponding to the molecular ions for $\mathrm{d}_{8}$-AEA and nondeuterated AEA, and at a $\mathrm{m} / \mathrm{z}$ of 412 and 404 , corresponding to the loss of a methyl group in both compounds. Selected ions for 2-AG were at a $\mathrm{m} / \mathrm{z}$ of 530 and 522, corresponding to the molecular ions of $\mathrm{d}_{8}-2-\mathrm{AG}$ and nondeuterated 2-AG, and at a $m / z$ of 515 and 507, corresponding to the loss of a methyl group in both compounds. The endocannabinoids were identified on the basis of the same retention time as the deuterated internal standards of the corresponding MS signals with the appropriate relative abundance. The amounts of AEA and 2-AG were calculated from the peak area ratios between the signals at a $m / z$ of 404 and 412 and at a $m / z$ of 507 and 515 , respectively. A linear correlation between these area ratios and the amounts of standards was observed in separate studies. In the case of 2-AG, the amount of the 1-(3) isomer, which is almost exclusively formed during tissue workup and lipid purification (Stella et al., 1997), was added to the amount of the 2-isomer.

\section{RESULTS}

The presence of $\mathrm{CB}_{1}$ and $\mathrm{CB}_{2}$ receptors and $\mathrm{FAAH}$ in the neonatal rat brain was verified by Western blotting; endocannabinoid levels were determined by isotope dilution GC/MS. Western blot analysis demonstrated the presence of the $\mathrm{CB}_{1}$ receptor in 7and 14-d-old rat brains, whereas the $\mathrm{CB}_{2}$ receptor could not be detected (Fig. 1). FAAH was also detected in 7-d-old rats (Fig. 1). Neonatal rat brains (P7) contained $32.5 \pm 6.5 \mathrm{pmol} / \mathrm{gm} \mathrm{AEA}$ and $1.17 \pm 0.22 \mathrm{nmol} / \mathrm{gm} 2-\mathrm{AG}$, which is in the same order of magnitude as reported previously (Sugiura et al., 1995; Kondo et al., 1998; Berrendero et al., 1999; Bisogno et al., 1999).

In our model, excitotoxicity was triggered by the unilateral intrastriatal injection of $0.5 \mu \mathrm{l}$ of ouabain $(1 \mathrm{~mm})$ in 7 - to 8 -d-old rats. Ouabain, a cardiac glycoside, inhibits $\mathrm{Na}^{+} / \mathrm{K}^{+}$-ATPases and induces cellular swelling, eventually leading to pancellular necrosis and infarction (Lees et al., 1990; Lees, 1991; Lees and Leong, 1994, 1995; Stelmashook et al., 1999). The acute cellular swelling is conveniently monitore by diff usion-weighted MRI. ADC maps of brain tissue water, calculated from diffusion-weighted MRIs acquired $15 \mathrm{~min}$ after ouabain injection, showed hypointensity regions with reduced $\mathrm{ADC}$ values $\left(\sim 0.65 \times 10^{-3} \mathrm{~mm}^{2} / \mathrm{sec}^{-1}\right)$ in the ipsilateral hemisphere in all animals (Fig. 2). Normal ADC values $\left(\sim 1.11 \times 10^{-3} \mathrm{~mm}^{2} / \mathrm{sec}^{-1}\right)$ were measured in the contralateral hemisphere of the ouabain-injected rats (Fig. 2) and in the brains of the control animals, which received only vehicle $(0.5$ $\mu \mathrm{l}$ of Tris- $\mathrm{HCl}, 40 \mathrm{~mm}, \mathrm{pH}$ 7.4). The reduction in ADC values in the ipsilateral hemisphere after ouabain injection is thought to reflect neuronal swelling (i.e., cytotoxic edema) because of a relocation of part of the extracellular water into depolarized cells (van Lookeren Campagne et al., 1994; Dijkhuizen et al., 1996). The same brain regions, including the caudate putamen, cortex, and hippocampus, were affected in all animals (Fig. 2). In this

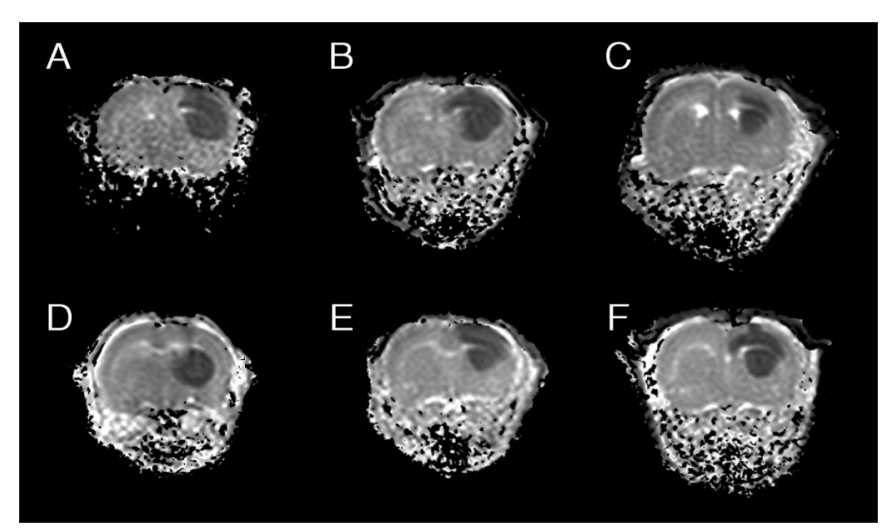

Figure 2. Coronal ADC maps of neonatal rat brains 15 min after ouabain injection. Hypointensities correlate to cytotoxic edema. Treatments: $A$, Vehicle; $B$, AEA (1 mg/kg); $C$, AEA $(10 \mathrm{mg} / \mathrm{kg}) ; D$, AEA plus $\mathrm{SR} 141716 \mathrm{~A}$ (10 and $3 \mathrm{mg} / \mathrm{kg}$, respectively); $E$, SR141716A $(3 \mathrm{mg} / \mathrm{kg}) ; F$, VDM11 (10 mg/kg).
A

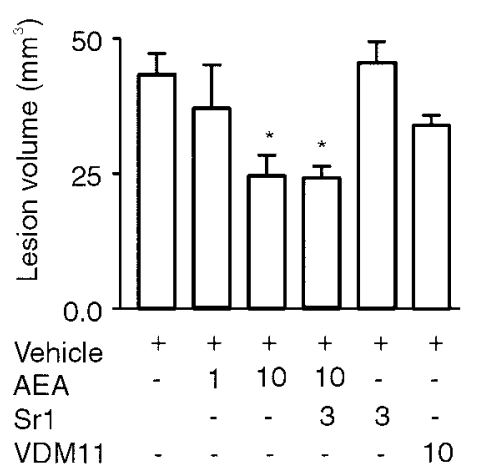

B

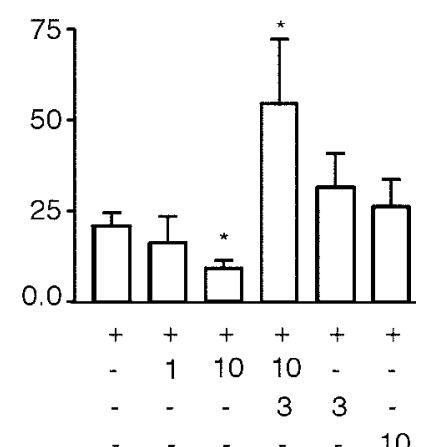

Figure 3. Mean lesion volumes $( \pm \mathrm{SE})$ of ouabain-injected rats on day 0 $(A)$ and day $7(B)$ based on ADC and $\mathrm{T}_{2}$ maps (hyperintensities), respectively. An asterisk denotes a $p$ value of $<0.05$ compared with vehicle-treated rats. The numbers at the bottom indicate the dose of compound in milligrams per kilogram. See Materials and Methods for lesion volume calculation.

acute phase, AEA reduced the volume of brain tissue with cytotoxic edema dose-dependently. The volume of tissue at risk to go into infarction was reduced by $43 \pm 15 \%(p<0.05)$ at $10 \mathrm{mg} / \mathrm{kg}$ AEA (Figs. 2 and $3 A$ ). This effect was observed at the borders of the affected tissue, namely the cortex and striatum. Coinjection of the $\mathrm{CB}_{1}$ receptor antagonist SR141716A with AEA did not reverse AEA action (Figs. 2 and $3 A$ ). Application of SR141716A or VDM11 (an endocannabinoid uptake inhibitor) alone did not change lesion volume at day 0 compared with vehicle-treated animals (Figs. 2 and $3 A$ ).

After $7 \mathrm{~d}$, the effect of AEA treatment on neuronal damage was assessed using $\mathrm{T}_{2}$-weighted imaging and verified by standard histology. Normal $\mathrm{T}_{2}$ values $\left(\mathrm{T}_{2}=73 \pm 1 \mathrm{msec}\right)$ were observed in contralateral hemispheres and in the brains of control animals (Fig. 4). The $\mathrm{T}_{2}$ maps of ouabain-injected animals demonstrated both hyperintensities and hypointensities (Fig. 4). Both types of $\mathrm{T}_{2}$ abnormalities indicate pathological changes. Hyperintense areas correspond to vasogenic edema, tissue loss, and ventricle dilation, whereas hypointensities can correlate to astrogliosis [i.e., phenotypic changes (hypertrophy)] and proliferation of astroglial cells in response to neuronal injury (Fig. 4) (Feuerstein et al., 1994; van Lookeren Campagne et al., 1994). Infarct size based on 


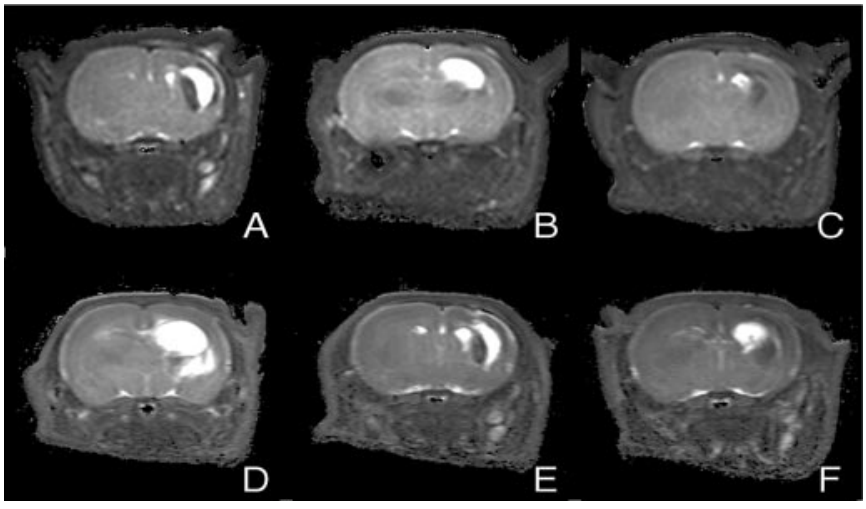

Figure 4. Coronal $\mathrm{T}_{2}$ maps of neonatal rat brains $7 \mathrm{~d}$ after ouabain injection. Hyperintensities correlate to vasogenic edema, tissue loss, and ventricle dilatation. Treatment: $A$, Vehicle; $B$, AEA $(1 \mathrm{mg} / \mathrm{kg}) ; C$, AEA $(10 \mathrm{mg} / \mathrm{kg}) ; D$, AEA plus SR141716A (10 and $3 \mathrm{mg} / \mathrm{kg}$, respectively); $E$, SR141716A (3 mg/kg); $F$, VDM11 (10 mg/kg).

$\mathrm{T}_{2}$ hyperintense abnormalities was dose-dependently reduced in the AEA-treated group compared with the control animals (Figs. $3 B$ and 4$)$. The infarct volume was $64 \pm 24 \%(p<0.05)$ at 10 $\mathrm{mg} / \mathrm{kg}$ AEA, smaller than in the vehicle-treated animals. Protection was primarily observed in the caudate putamen, cortex, and hippocampus. This effect was blocked by the $\mathrm{CB}_{1}$ antagonist $(p<$ 0.05 ) (Figs. $3 B$ and 4 ). The infarct was $\sim 2.5$-fold larger than that in vehicle-treated animals $(p<0.05)$ and primarily involved the hippocampus and caudate putamen. Application of SR141716A and VDM11 alone did not affect lesion size. Conventional histology (Nissl and hematoxylin-eosin staining) showed a similar lesion pattern on brain sections and confirmed the assessment made by $\mathrm{T}_{2}$ map analysis (data not shown).

The hypointense regions on the $T_{2}$ maps corresponded to regions exhibiting increased staining for GFAP on brain sections of ouabain-treated rats, which is typical of astrogliosis (Fig. $5 A-D$ ) (Van der Stelt et al., 2001). No indications for hemorrhage were found. Astrogliotic tissue constituted $\sim 44 \%$ of the lesion on $\mathrm{T}_{2}$ maps of nontreated animals and usually surrounded the edematous tissue and the dilated ventricles (Fig. 5B). The volume of astrogliotic tissue in AEA-treated rats was not affected compared with nontreated rats $(p>0.05)$, which is in accordance with our previous observation that $\mathrm{THC}$ reduces astrogliosis via a $\mathrm{CB}_{1}$ and $\mathrm{CB}_{2}$-independent mode of action in our model (Van der Stelt et al., 2001) (our unpublished results). This reinforces the notion that classical cannabinoids also have other modes of action in addition to their interaction with the $\mathrm{CB}_{1}$ and $\mathrm{CB}_{2}$ receptors (Burstein, 1999).

Finally, rat brain endocannabinoid levels were measured 2, 8, and $24 \mathrm{hr}$ after ouabain or vehicle injection. No rises in concentrations of AEA and 2-AG were observed after inducing acute neuronal damage in the ipsilateral hemisphere (Fig. 6). There were no significant differences in endocannabinoid levels between ipsilateral and contralateral hemispheres and between vehicleand ouabain-injected animals (data not shown).

\section{DISCUSSION}

The (patho)physiological role of the endogenous cannabinoid system is beginning to be unraveled (Giuffrida et al., 1999; Galve-Roperh et al., 2000; Di Marzo et al., 2001). It has been postulated that the endocannabinoid system may serve to establish a defense system for the brain during neurotoxicity and

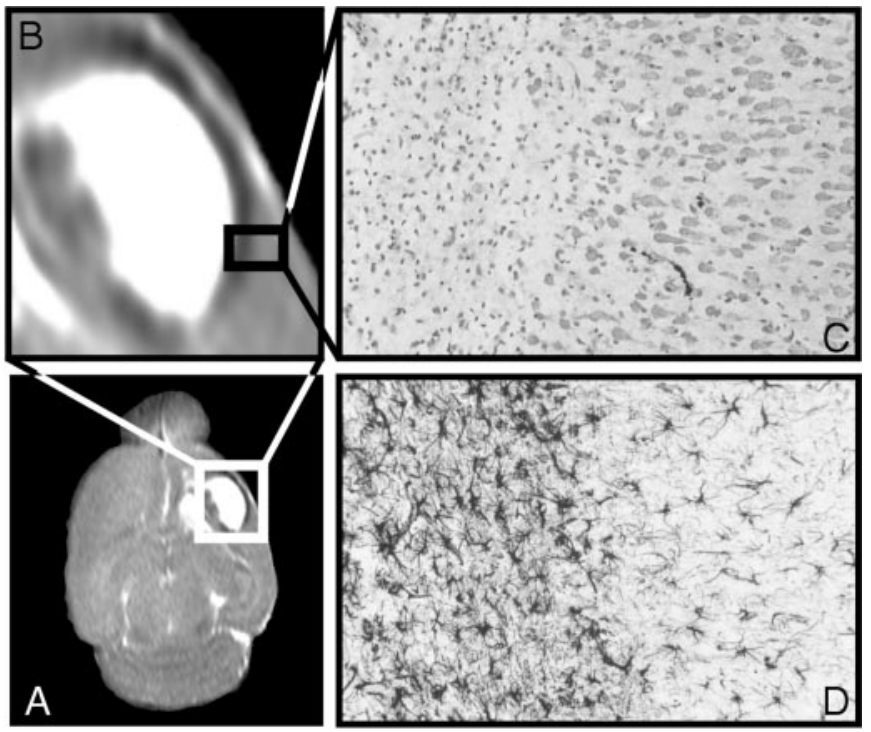

Figure 5. Transversal $\mathrm{T}_{2}$ map $(A)$ of an ouabain-injected animal showing that vasogenic edema is surrounded by astrogliosis (hypointense area) $(B)$. Nissl-staining $(C)$ and GFAP-staining $(D)$ of a brain section of an ouabain-injected rat demonstrate a sharp line between affected and healthy tissue.

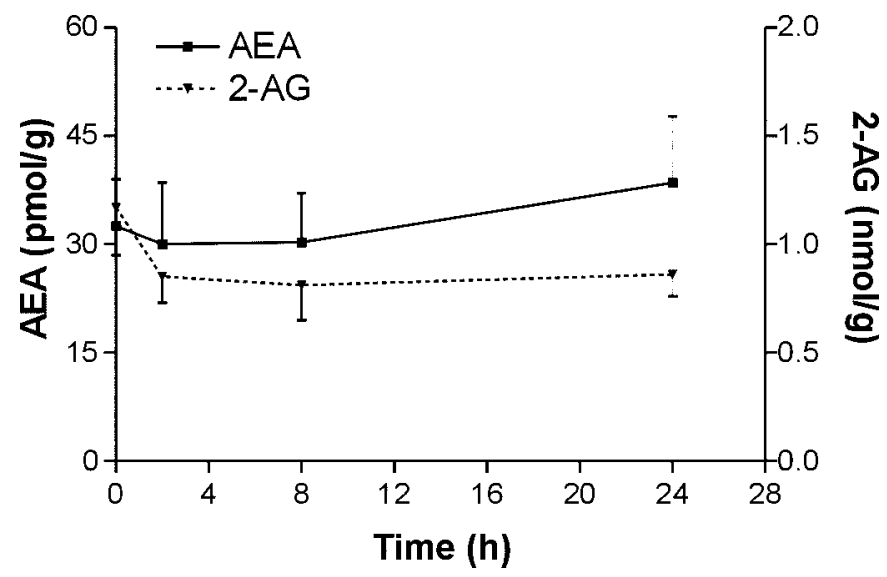

Figure 6. Endocannabinoid levels in a rat brain 2, 8, and $24 \mathrm{hr}$ after ouabain injection.

ischemia (H. S. Hansen et al., 2000; Jin et al., 2000; Van der Stelt et al., 2001). Yet the therapeutic effects of classical and synthetic cannabinoids were contradictory in models in which transient (20-120 min) or permanent cerebral ischemia was induced (Nagayama et al., 1999; Louw et al., 2000; C. J. Hillard, personal communication). Because the cannabinoid system has complex (cerebro)vascular effects (Randall and Kendall, 1998; Kunos et al., 2000), this might explain the difference in therapeutic outcome in the various models of stroke.

We investigated the presumed neuroprotective properties of the most studied endocannabinoid, AEA, in an in vivo model of secondary excitotoxicity, in which neuronal injury was induced by unilateral intrastriatal injection of the $\mathrm{Na}^{+} / \mathrm{K}^{+}$-ATPase inhibitor ouabain without direct cerebrovascular intervention. Ouabain rapidly perturbs ion homeostasis and induces cellular swelling and glutamate-dependent damage of cells, which can be prevented in part by blockade of the NMDA receptor (Lees et al., 
1990; Cousin et al., 1995; Greene and Greenamyre, 1996; Basarsky et al., 1999).

Diff usion-weighted MRI data acquired 15 min after the injection of ouabain showed that exogenous AEA dose-dependently reduces in vivo cellular swelling in the early phase after the induction of excitotoxicity. We have shown previously that THC was able to reduce in vivo cellular swelling in a $\mathrm{CB}_{1}$-mediated manner in the same model (Van der Stelt et al., 2001). The reduction in cellular swelling was not attenuated by the $\mathrm{CB}_{1}$ antagonist SR141716A. Because there are no $\mathrm{CB}_{2}$ receptors detected in the brain, the early in vivo neuroprotective action of AEA does not seem to be mediated via the $\mathrm{CB}_{1}$ or $\mathrm{CB}_{2}$ receptors.

The failure of SR141716A to block a reduction in cytotoxic edema by AEA in the early phase does not seem to be a matter of dose and pharmacokinetics. The antagonist $(3 \mathrm{mg} / \mathrm{kg}) \mathrm{did}$ block the late effects (after $7 \mathrm{~d})$ of AEA $(10 \mathrm{mg} / \mathrm{kg})$. In addition, a lower dose of SR141716A (1 mg/ $\mathrm{kg}$ ) was more than sufficient to block the neuroprotective actions of THC $(1 \mathrm{mg} / \mathrm{kg})$ at days 0 and 7 (Van der Stelt et al., 2001). It is noteworthy that THC is a more potent agonist of the $\mathrm{CB}_{1}$ receptor than AEA. In addition, SR141716A is effective in blocking the behavioral effects of THC in the mouse "tetrad" with AD50s of $\sim 0.1 \mathrm{mg} / \mathrm{kg}$, whereas some of the actions of AEA were insensitive to SR141716A (Adams et al., 1998). Moreover, some of the behavioral actions of AEA in mice were still observed in the $\mathrm{CB}_{1}$ knock-out mice (Di Marzo et al., 2000a). Others (Sinor et al., 2000) have shown that neuroprotection of AEA in in vitro experiments was also independent of $\mathrm{CB}_{1}$ and $\mathrm{CB}_{2}$ receptors.

Recent data demonstrate that AEA is capable of interacting with other molecular targets, such as 5-hydroxytryptamine receptors, NMDA receptors, vanilloid receptors, L-type calcium channels, Shaker-related $\mathrm{K}^{+}$channels, TASK-1 channels, a non- $\mathrm{CB}_{1}$ G-protein-coupled AEA receptor in astrocytes, and a non- $\mathrm{CB}_{1}$, non- $\mathrm{CB}_{2}$ G-protein-coupled receptor for AEA and WIN55.212-2 in the mouse brain (Howlett and Mukhopadhyay, 2000; Breivogel et al., 2001), some of which may contribute to a reduction in cellular swelling. For example, the inhibition of gap junctions and intracellular calcium signaling in striatal astrocytes by the non$\mathrm{CB}_{1}$ G-protein-coupled AEA receptor (Venance et al., 1995) or the inhibition of L-type calcium channels (Johnson et al., 1993) may prevent glutamate exocytosis and the spreading of excitotoxicity. We cannot rule out the possibility that metabolites of AEA may account for some of the observed effects. Additional studies are necessary to understand the molecular mechanism of AEAinduced reduction of cytotoxic edema.

$\mathrm{T}_{2}$-weighted MRI data recorded 1 week after ouabain injection showed that exogenous AEA reduced neuronal damage by $64 \pm$ $24 \%(p<0.05)$. Compared with the early phase, AEA-induced neuroprotection was blocked by the $\mathrm{CB}_{1}$ receptor antagonist after $7 \mathrm{~d}$. This can be explained by the different stages in the cascade of events induced by excitotoxicity. Calcium entry is held responsible for delayed neurodegenerative events, which can occur even if the initial cellular swelling is reversed or prevented (Choi, 1987; Doble, 1999). We have suggested previously that THC protected rat brains in the late phase via the $\mathrm{CB}_{1}$-mediated closing of $\mathrm{N}$ and $\mathrm{P} / \mathrm{Q}$-type calcium channels and inhibition of glutamatergic transmission in the same model (Huang et al., 2001; Van der Stelt et al., 2001). It is reasonable to assume that this $\mathrm{CB}_{1}$-mediated process of closing voltage-sensitive calcium channels also contributes to the observed neuroprotection of AEA after $7 \mathrm{~d}$. As noted before for THC, AEA-induced neuroprotection was observed in brain regions such as the cortex, striatum, and hippocampus (Van der Stelt et al., 2001).

Strikingly, the combination of AEA and the antagonist produced an infarct that was 2.5 times larger than that seen for the control group. This observation is not likely to be explained by (1) blockade of the effect of endogenously released cannabinoids, (2) inverse agonism of SR141716A, or (3) toxic effects of SR141716A. In fact, treatment of rats with SR141716A at 1 and $3 \mathrm{mg} / \mathrm{kg}$ or with SR141716A plus THC (1 mg/ $\mathrm{kg})$ did not increase infarct size significantly (Van der Stelt et al., 2001). In addition, endocannabinoid levels do not appear to increase after ouabain injection.

Hampson et al. (1998) have shown that AEA can enhance calcium influx presumably via direct activation of NMDA receptors. This enhancement could only be observed when $\mathrm{CB}_{1}$ receptors were blocked by SR141716A. This might explain the extra deleterious effect of the combination AEA and SR141716A. Interestingly, the site and size of the infarcted region in these animals were similar to those observed in animals that received a unilateral intrastriatal injection with NMDA (our unpublished results).

Several lines of evidence gained in this study indicate that there is no endogenous cannabinoid tone controlling the acute neuronal damage induced by ouabain: (1) No increases in AEA and 2-AG levels were detected at 2, 8, or $24 \mathrm{hr}$ after ouabain injection. (2) Application of SR141716A alone (3 mg/ kg) did not increase the lesion volume at day 0 or at day 7 . This implies that activation of $\mathrm{CB}_{1}$ receptors by constitutive levels of AEA, 2-AG, or any other novel $\mathrm{CB}_{1}$ ligand, such as noladin ether (Hanus et al., 2001), does not tonically protect the brain. (3) The AEA uptake inhibitor VDM11 did not reduce neuronal swelling at day 0 , nor did it reduce the infarct volume after $7 \mathrm{~d}$. This also argues against a $\mathrm{CB}_{1}$ receptor-independent tonic protective role of endogenous AEA and 2-AG. Thus, in our in vivo model of acute neuronal damage, the data do not support the previously proposed role of the endogenous cannabinoid system in neuroprotection.

However, we cannot exclude the possibility that technical issues have prevented the detection of a tonic protection by endocannabinoids. The lesion was considered pathological when ADC or $\mathrm{T}_{2}$ values differed more than twice the $\mathrm{SD}$ of the mean value in the contralateral hemisphere. Thus, the periphery of the infarct with smaller changes in ADC or $\mathrm{T}_{2}$ was not taken into account, but may have benefited from a possible endogenous release of cannabinoids. In addition, endocannabinoid levels were measured in total hemispheres, and a possible local upregulation of AEA and 2-AG could have been missed. However, this last possibility appears unlikely if one considers the massive accumulation of endocannabinoids observed in other models of neuronal injury (Sugiura et al., 2000; Hansen et al., 2001).

In addition, Hansen et al. (2001) have demonstrated that the increase in $\mathrm{N}$-acylphosphatidylethanolamines varies in different in vivo models of neuronal damage and is dependent on the type of cell death. High levels of these lipids, which act as biosynthetic precursors for AEA and its congeners, were found in NMDAinjected neonatal rats. However, only moderate and low increases were observed in a closed head-injury model and in an apoptotic model, respectively. Although our model does not represent a model of apoptotic cell death, ouabain-induced injury was not severe enough to elicit endocannabinoid formation.

In this respect it is interesting to note that Wilson and Nicoll (2001) have suggested that release of relevant levels of endocannabinoids probably only occurs in response to particularly intense 
stimuli. Thus, endogenous AEA may only be released after the intense stimulus, and, hence, too late to exert a protective action, whereas exogenous AEA may inhibit the ouabain-induced glutamatergic transmission, thereby preventing spreading and reducing the effect of the toxic stimulus. This explanation is consistent with recent studies in which endogenous cannabinoids were shown to mediate retrograde signaling from postsynaptic neurons to presynaptic terminals in hippocampal and cerebellar synapses (Kreitzer and Regehr, 2001; Ohno-Shosaku et al., 2001; Wilson and Nicoll, 2001).

In summary, we were able to accumulate data that strongly suggest that there is no endogenous endocannabinoid tone controlling the acute neuronal damage induced by ouabain. In contrast, our data, together with previous reports, indicate that exogenous AEA can protect the neonatal rat brain via a variety of mechanisms. Although our findings do question the role of the endogenous cannabinoid system in establishing a tonic brain defense system in our model, AEA may be used as a structural template to develop new neuroprotective agents.

\section{REFERENCES}

Adams IB, Compton DR, Martin BR (1998) Assessment of anandamide interaction with the cannabinoid brain receptor: SR 141716A antagonism studies in mice and autoradiographic analysis of receptor binding in rat brain. J Pharmacol Exp Ther 284:1209-1217.

Baker D, Pryce G, Croxford JL, Brown P, Pertwee RG, Makriyannis A, Khanolkar A, Layward L, Fezza F, Bisogno T, Di Marzo V (2001) Endocannabinoids control spasticity in a multiple sclerosis model. FASEB J 15:300-302.

Basarsky TA, Feighan D, MacVicar BA (1999) Glutamate release through volume-activated channels during spreading depression. J Neurosci 19:6439-6445.

Berrendero F, Sepe N, Ramos JA, Di Marzo V, Fernandez-Ruiz JJ (1999) Analysis of cannabinoid receptor binding and mRNA expression and endogenous cannabinoid contents in the developing rat brain during late gestation and early postnatal period. Synapse 33:181-191.

Bisogno T, Sepe N, Melck D, Maurelli S, De Petrocellis L, Di Marzo V (1997) Biosynthesis, release, and degradation of the novel endogenous cannabimimetic metabolite 2-arachidonoylglycerol in mouse neuroblastoma cells. Biochem J 322:671-677.

Bisogno T, Berrendero F, Ambrosino G, Cebeira M, Ramos JA, Fernandez-Ruiz JJ, Di Marzo V (1999) Brain regional distribution of endocannabinoids: implications for their biosynthesis and biological function. Biochem Biophys Res Commun 256:377-380.

Bligh EG, Dyer WJ (1959) A rapid method of total lipid extraction and purification. Can J Biochem Physiol 37:911-917.

Breivogel CS, Griffin G, Di Marzo V, Martin BR (2001) Discovery of a new G-protein-coupled cannabinoid receptor in mouse brain. Mol Pharmacol 60(1):155-163.

Burstein SH (1999) The cannabinoid acids: nonpsychoactive derivatives with therapeutic potential. Pharmacol Ther 82:87-96.

Choi DW (1987) Ionic dependence of glutamate neurotoxicity. J Neurosci 7:369-379.

Cousin MA, Nicholls DG, Pocock JM (1995) Modulation of ion gradients and glutamate release in cultured cerebellar granule cells by ouabain. J Neurochem 64:2097-2104.

de Graaf RA, Braun KPJ, Nicolay K (2001) Single-shot diffusion trace 1H NMR spectroscopy. Magn Reson Med 45:741-748.

De Petrocellis L, Bisogno T, Davis JB, Pertwee RG, Di Marzo V (2000) Overlap between the ligand recognition properties of the anandamide transporter and the VR1 vanilloid receptor: first inhibitors of anandamide uptake with negligible capsaicin-like activity. FEBS Lett 483:52-56.

Dijkhuizen RM, van Lookeren Campagne M, Niendorf T, Dreher W, van der Toorn A, Hoehn-Berlage M, Verheul HB, Tulleken CA, Leibfritz D, Hossmann KA, Nicolay K (1996) Status of the neonatal rat brain after NMDA-induced excitotoxic injury as measured by MRI, MRS, and metabolic imaging. NMR Biomed 9:84-92.

Di Marzo V, Melck D, Bisogno T, De Petrocellis L (1998) Endocannabinoids: endogenous cannabinoid receptor ligands with neuromodulatory action. Trends Neurosci 21:521-528.

Di Marzo V, Breivogel CS, Tao Q, Bridgen DT, Razdan RK, Zimmer AM, Zimmer A, Martin BR (2000a) Levels, metabolism, and pharmacological activity of anandamide in $\mathrm{CB}(1)$ cannabinoid receptor knockout mice: evidence for non- $\mathrm{CB}(1)$, non- $\mathrm{CB}(2)$ receptor-mediated actions of anandamide in mouse brain. J Neurochem 75:2434-2444.

Di Marzo V, Hill MP, Bisogno T, Crossman AR, Brotchie JM (2000b)
Enhanced levels of endogenous cannabinoids in the globus pallidus are associated with a reduction in movement in an animal model of Parkinson's disease. FASEB J 14:1432-8143.

Di Marzo V, Goparaju SK, Wang L, Liu J, Batkai S, Jarai Z, Fezza F, Miura GI, Palmiter RD, Sugiura T, Kunos G (2001) Leptin-regulated endocannabinoids are involved in maintaining food intake. Nature 410:822-825.

Dirnagl U, Iadecola C, Moskowitz MA (1999) Pathobiology of ischaemic stroke: an integrated view. Trends Neurosci 22:391-397.

Doble A (1999) The role of excitotoxicity in neurodegenerative disease: implications for therapy. Pharmacol Ther 81:163-221.

Feuerstein GZ, Liu T, Barone FC (1994) Cytokines, inflammation, and brain injury: role of tumor necrosis factor- $\alpha$. Cerebrovasc Brain Metab Rev 6:341-360.

Galve-Roperh I, Sanchez C, Cortes ML, del Pulgar TG, Izquierdo M, Guzman M (2000) Anti-tumoral action of cannabinoids: involvement of sustained ceramide accumulation and extracellular signal-regulated kinase activation. Nat Med 6:313-319.

Giuffrida A, Parsons LH, Kerr TM, Rodriguez de Fonseca F, Navarro M, Piomelli D (1999) Dopamine activation of endogenous cannabinoid signaling in dorsal striatum. Nat Neurosci 2:358-363.

Greene JG, Greenamyre JT (1996) Manipulation of membrane potential modulates malonate-induced striatal excitotoxicity in vivo. J Neurochem 66:637-643.

Hampson AJ, Bornheim LM, Scanziani M, Yost CS, Gray AT, Hansen BM, Leonoudakis DJ, Bickler PE (1998) Dual effects of anandamide on NMDA receptor-mediated responses and neurotransmission. J Neurochem 70:671-676.

Hansen HH, Hansen SH, Schousboe A, Hansen HS (2000) Determination of the phospholipid precursor of anandamide and other $N$-acylethanolamine phospholipids before and after sodium azideinduced toxicity in cultured neocortical neurons. J Neurochem 75:861-871.

Hansen HH, Ikonomidou C, Bittigau P, Hansen SH, Hansen HS (2001) Accumulation of the anandamide precursor and other $N$-acylethanolamine phospholipids in infant rat models of in vivo necrotic and apoptotic neuronal death. J Neurochem 76:39-46.

Hansen HS, Lauritzen L, Moesgaard B, Strand AM, Hansen HH (1998) Formation of $N$-acyl-phosphatidylethanolamines and $N$-acetylethanolamines: proposed role in neurotoxicity. Biochem Pharmacol $55: 719-725$

Hansen HS, Moesgaard B, Hansen HH, Schousboe A, Petersen G (1999) Formation of $N$-acyl-phosphatidylethanolamine and $N$-acylethanolamine (including anandamide) during glutamate-induced neurotoxicity. Lipids 34:S327-S330.

Hansen HS, Moesgaard B, Hansen HH, Petersen G (2000) $N$-Acylethanolamines, precursor phospholipids: relation to cell injury. Chem Phys Lipids 108:135-150.

Hanus L, Abu-Lafi S, Fride E, Breuer A, Vogel Z, Shalev DE, Kustanovich I, Mechoulam R (2001) 2-Arachidonyl glyceryl ether, an endogenous agonist of the cannabinoid CB1 receptor. Proc Natl Acad Sci USA 98:3662-3665.

Howlett AC, Mukhopadhyay S (2000) Cellular signal transduction by anandamide and 2-arachidonoylglycerol. Chem Phys Lipids 108:53-70.

Huang CC, Lo SW, Hsu KS (2001) Presynaptic mechanisms underlying cannabinoid inhibition of excitatory synaptic transmission in rat striatal neurons. J Neurophysiol 532 3:731-748.

Hurn PD, Macrae IM (2000) Estrogen as a neuroprotectant in stroke. J Cereb Blood Flow Metab 20:631-652.

Jin KL, Mao XO, Goldsmith PC, Greenberg DA (2000) CB1 cannabinoid receptor induction in experimental stroke. Ann Neurol 48:257-261.

Johnson DE, Heald SL, Dally RD, Janis RA (1993) Isolation, identification, and synthesis of an endogenous arachidonic amide that inhibits calcium channel antagonist 1,4-dihydropyridine binding. Prostaglandins Leukot Essent Fatty Acids 48:429-437.

Kempe K, Hsu FF, Bohrer A, Turk J (1996) Isotope dilution mass spectrometric measurements indicate that arachidonylethanolamide, the proposed endogenous ligand of the cannabinoid receptor, accumulates in rat brain tissue postmortem but is contained at low levels in or is absent from fresh tissue. J Biol Chem 271:17287-17295.

Kondo S, Kondo H, Nakane S, Kodaka T, Tokumura A, Waku K, Sugiura $\mathrm{T}$ (1998) 2-Arachidonoylglycerol, an endogenous cannabinoid receptor agonist: identification as one of the major species of monoacylglycerols in various rat tissues, and evidence for its generation through $\mathrm{Ca}^{2+}$-dependent and -independent mechanisms. FEBS Lett 429:152-156.

Kreitzer AC, Regehr WG (2001) Retrograde inhibition of presynaptic calcium influx by endogenous cannabinoids at excitatory synapses onto Purkinje cells. Neuron 29:717-727.

Kunos G, Jarai Z, Varga K, Liu J, Wang L, Wagner JA (2000) Cardiovascular effects of endocannabinoids: the plot thickens. Prostaglandins Other Lipid Mediat 61:71-84.

Lees GJ (1991) Inhibition of sodium-potassium-ATPase: a potentially 
ubiquitous mechanism contributing to central nervous system neuropathology. Brain Res Brain Res Rev 16:283-300.

Lees GJ, Leong W (1994) Brain lesions induced by specific and nonspecific inhibitors of sodium-potassium ATPase. Brain Res 649:225-233.

Lees GJ, Leong W (1995) The sodium-potassium ATPase inhibitor ouabain is neurotoxic in the rat substantia nigra and striatum. Neurosci Lett 188:113-116.

Lees GJ, Lehmann A, Sandberg M, Hamberger A (1990) The neurotoxicity of ouabain, a sodium-potassium ATPase inhibitor, in the rat hippocampus. Neurosci Lett 120:159-162.

Louw DF, Yang FW, Sutherland GR (2000) The effect of $\Delta$-9tetrahydrocannabinol on forebrain ischemia in rat. Brain Res 857:183-187.

Nagayama T, Sinor AD, Simon RP, Chen J, Graham SH, Jin K, Greenberg DA (1999) Cannabinoids and neuroprotection in global and focal cerebral ischemia and in neuronal cultures. J Neurosci 19:2987-2995.

Ohno-Shosaku T, Maejuma T, Kano M (2001) Endogenous cannabinoids mediate retrograde signals from depolarized postsynaptic neurons to presynaptic terminals. Neuron 29:729-738.

Pertwee RG (1997) Pharmacology of cannabinoid CB1 and CB2 receptors. Pharmacol Ther 74:129-180.

Picano E, Abbracchio MP (2000) Adenosine, the imperfect endogenous anti-ischemic cardio-neuroprotector. Brain Res Bull 52:75-82.

Randall MD, Kendall DA (1998) Endocannabinoids: a new class of vasoactive substances. Trends Pharmacol Sci 19:55-58.

Reiter RJ (1998) Oxidative damage in the central nervous system: protection by melatonin. Prog Neurobiol 56:359-384.

Renolleau S, Aggoun-Zouaoui D, Ben-Ari Y, Charriaut-Marlangue C (1998) A model of transient unilateral focal ischemia with reperfusion in the P7 neonatal rat: morphological changes indicative of apoptosis. Stroke 29:1454-1461.

Schmid HH, Schmid PC, Natarajan V (1990) N-acylated glycerophospholipids and their derivatives. Prog Lipid Res 29:1-43.

Shen M, Thayer SA (1998) Cannabinoid receptor agonists protect cultured rat hippocampal neurons from excitotoxicity. Mol Pharmacol $54: 459-462$.
Shen M, Piser TM, Seybold VS, Thayer SA (1996) Cannabinoid receptor agonists inhibit glutamatergic synaptic transmission in rat hippocampal cultures. J Neurosci 16:4322-4334.

Sinor AD, Irvin SM, Greenberg DA (2000) Endocannabinoids protect cerebral cortical neurons from in vitro ischemia in rats. Neurosci Lett 278:157-160.

Stella N, Schweitzer P, Piomelli D (1997) A second endogenous cannabinoid that modulates long-term potentiation. Nature 388:773-778.

Stelmashook EV, Weih M, Zorov D, Victorov I, Dirnagl U, Isaev N (1999) Short-term block of $\mathrm{Na}^{+} / \mathrm{K}^{+}$-ATPase in neuro-glial cell cultures of cerebellum induces glutamate-dependent damage of granule cells. FEBS Lett 456:41-44.

Sugiura T, Kondo S, Sukagawa A, Nakane S, Shinoda A, Itoh K, Yamashita A, Waku K (1995) 2-Arachidonoylglycerol: a possible endogenous cannabinoid receptor ligand in brain. Biochem Biophys Res Commun 215:89-97.

Sugiura T, Yoshinaga N, Kondo S, Waku K, Ishima Y (2000) Generation of 2-arachidonoylglycerol, an endogenous cannabinoid receptor ligand, in picrotoxinin-administered rat brain. Biochem Biophys Res Commun 271:654-658.

Van der Stelt M, Veldhuis WB, Bär PR, Veldink GA, Vliegenthart JFG, Nicolay K (2001) Neuroprotection by $\Delta^{9}$-tetrahydrocannabinol, the main active compound in marijuana, against ouabain-induced in vivo excitotoxicity. J Neurosci 21:6475-6479.

van Lookeren Campagne M, Verheul JB, Nicolay K, Balazs R (1994) Early evolution and recovery from excitotoxic injury in the neonatal rat brain: a study combining magnetic resonance imaging, electrical impedance, and histology. J Cereb Blood Flow Metab 14:1011-1023.

Vannucci RC (1990) Experimental biology of cerebral hypoxia-ischemia: relation to perinatal brain damage. Pediatr Res 27:317-326.

Venance L, Piomelli D, Glowinski J, Giaume C (1995) Inhibition by anandamide of gap junctions and intercellular calcium signalling in striatal astrocytes. Nature 376:590-594.

Wilson RI, Nicoll RA (2001) Endogenous cannabinoids mediate retrograde signalling at hippocampal synapses. Nature 410:588-592. 